\title{
Do Environmental Norms and Climate Change Perceptions Influence Mitigation Behaviour? Thailand as a Case Study
}

\author{
Suthirat Kittipongvises and Takashi Mino
}

\begin{abstract}
Global climate change is now widely recognized as one of the most significant environmental threats of the 21st century. The need to reduce its impact requires the sharing of responsibilities between organizing authorities and the local public. It is widely acknowledged that, to date, the current state of scientific knowledge on climate change is objective. This could lead to it being more or less directly translated into actions. This study aims to investigate which factors are motivating people to undertake mitigation measures, with a particular focus on environmental norms and climate change perceptions held by the rural citizens of Thailand. Questionnaires were distributed to 253 selected households in village 4 of Nongbuasala, Nakhon Ratchasima province, Thailand. Statistical analysis indicated that there was a significantly positive correlation between environmental norms and climate change perception $(r=.383, p<0.01)$. Both perception of climate change as a phenomenon and concern for the environment were found to be significantly positive correlated with the behavioural intention to take voluntary mitigation actions $(p \leq 0.05)$. Specifically, only the intentions to implement afforestation and reduce plastic consumption were significantly positive correlations with the perceptions of climate change. And beside this, the willingness to eliminate the use of plastic, increase waste stream recycling and implement afforestation activities ought to be positively related to environmental norms held by the respondents $(r=.325$ to $r$ $=.058 ; p \leq 0.05)$. Implications for further research were finally raised.
\end{abstract}

Index Terms-Climate change perceptions, environmental norms, mitigation behaviour, Thailand.

\section{INTRODUCTION}

The urgent need to mitigate the problem of climate change is now becoming more widely understood by both academia and policy makers, but at the same time public awareness and actions often lag far behind [1]. Until recently, despite increasing consensus on the subject, many people around the world are still skeptical about the concept of climate change [2], [3]. A series of international studies conducted by [4] revealed that most respondents do not seem to exactly understand the mechanisms of how climate change work and/or what its cause is. To exemplify this, in Thailand, a

Manuscript received November 12, 2012; revised February 27, 2013 This work was financially supported by the Japanese government.

S. Kittipongvises is with the Graduate Program in Sustainability Science, Global Leadership Initiative (GPSS-GLI), the University of Tokyo, 277-8563, Japan (e-mail: suthirat.k@gmail.com).

T. Mino is with the GPSS-GLI, the University of Tokyo. He is now Chair Professor of the Department of Environmental Studies, The University of Tokyo, 277-8563, Japan. national survey showed that only $9 \%$ of Thai respondents correctly identified burning fossil fuels as the primary cause of climate change [5].

A large body of empirical literature also indicated that many people remain reluctant to change their behaviour to deal with climate change problem. Indeed, the relationship between knowledge, attitudes and behaviours has long been debated for more than a century (e.g., the theory of planned behaviour; value-norm-belief (VNB); and information deficit model). [6] articulated that knowledge is often recognised as a background factor that influences a person's attitude and subjective norm to behaviour intention and gives the possibility of association between attitude and actual behaviour (See Fig. 1).

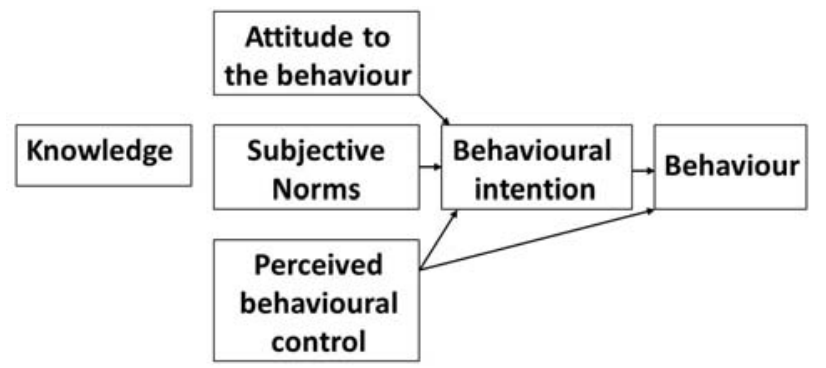

Fig. 1. Theory of Planned Behaviour [6].

However, interestingly, it is important to realise that there are a few studies which examine the predictors of public perception and action in response to climate change, and even fewer set in Thailand. In most cases, past research has also failed to clearly address the following fundamental issues: Are people reluctant to take responsibility because they lack the knowledge to do so? Or, perhaps they don't care enough to make changes. Subsequently, the aim of this study was to investigate the linkage between climate change perceptions, environmental norms and their preferences for climate change mitigation actions in Thailand, a country case study.

\section{MATERIAL AND MethodS}

This paper draws on mixed research methods. Literature reviews, semi-structured interviews, community observation and questionnaire surveys were used.

\section{A. Literature Rreviews}

Basically, climate change is caused by increasing concentration of greenhouse gases (i.e. carbon dioxide; $\mathrm{CO}_{2}$ ) in the atmosphere. There is very strong evidence that the main contribution to the problem is human activity, most significantly the burning of fossil fuels for electricity and 
power generation. Taken globally, the total world energy consumption and $\mathrm{CO}_{2}$ emission continue to increase steadily. In 2009, the International Energy Agency [7] revealed that electricity and heat generation produced nearly half $(>40 \%)$ of global $\mathrm{CO}_{2}$ emissions.

To act to mitigate undesirable climate change, the US Environmental Protection Agency has been exploring a variety of mitigation measures in the household sector include:

- Save energy by switching appliances off when not in use.

- Improve energy efficiency by replacing household's old applicant with an energy star.

- Implement the 3Rs by reducing, reusing and recycling waste such as plastic, glass, metal.

- Build a green in backyard.

\section{B. Case Study}

Local people who lived in village 4 of the Nongbuasala sub district, Muang district, Nakhon Ratchasima province, the Northeast region of Thailand was considered as the target population in this study (See Fig. 2).

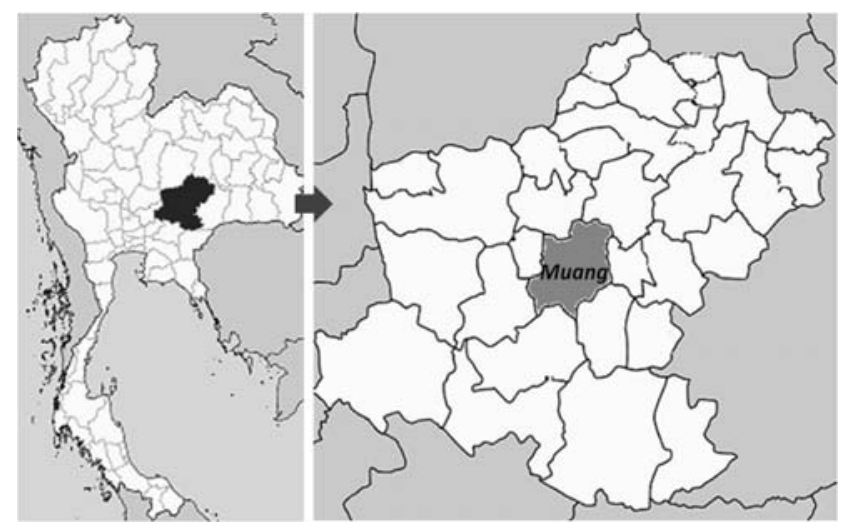

Fig. 2. Study area, Muang Nakhon Ratchasima district, Thailand

Crucially, in 2008, according to the survey of local opinion toward environmental and climate benefits from waste-to-energy project in this community, [8] found that the majority of respondents did not fully understand the key concepts of climate change and related issues. Therefore, in this study, a random sample of 253 households (among the total population of 724 households) was classified using a probability-proportional-to-size sample selection with $95 \%$ confidence interval.

\section{Questionnaire}

To begin with, all the respondents were simply asked open-ended questions. For example, Are you concerned about the environment in general? Do you know about global climate change? Does climate change and related topics bring anything else to your mind? Do you want to do something to help combat climate change? Further to this, a questionnaire was developed based on multidisciplinary reviews. The respondents were asked to use a Likert scale numerical rating from 'strongly disagree' to 'strongly agree' for each statement in a series of questions. In this context, 'perceptions' were explored using respondents' understanding of the general notion of climate change (e.g. definition and its cause). As mentioned above, according to USEPA, a variety of climate change mitigation measures include: i) saving household energy, ii) improving household energy efficiency, iii) enhancing recycling practices, iv) reducing plastic consumption, and v) increasing afforestation (Appendix A). All statistical analyses were computed using SPSS software at less than or equal to 0.05 significance level.

\section{RESUlTS AND DISCUSSION}

\section{A. Survey and Interviews: Perception}

Although half of respondents reported that they had heard and/or seen about climate change, there were still plenty of misconceptions around these issues in general. With these main categories, the majority of respondents tended to perceive climate change and extreme weather events in their local area (e.g. drought and extreme temperature) as meaning the same thing. Most of them also identified deforestation as the 'primary cause' of climate change rather than their use of fossil fuels. Specifically, in terms of mitigation measures, the majority of respondents perceive that increasing afforestation and reducing the usage of plastic were considered to be one method of mitigating the impacts of global climate change. Nearly a half of respondents also believe that saving household energy consumption can reduce their contribution to the problem. Whereas, a relatively small number knew about the climate benefits from waste recycling and improving energy efficiency of household appliances, as illustrated in Fig. 3.

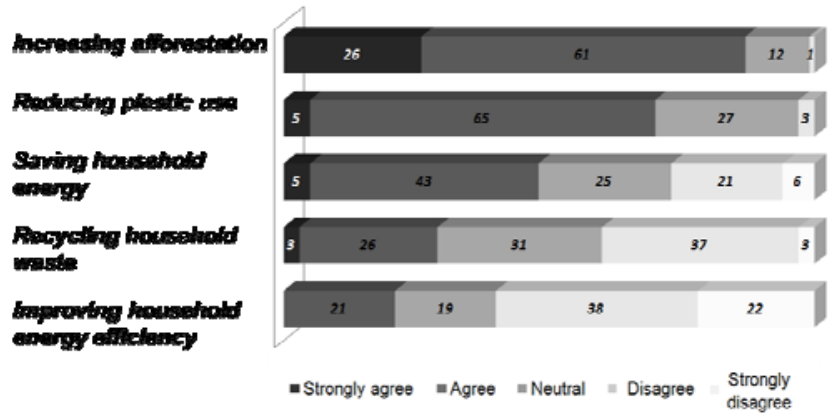

Fig. 3. Local people's perceptions of climate change mitigation activities

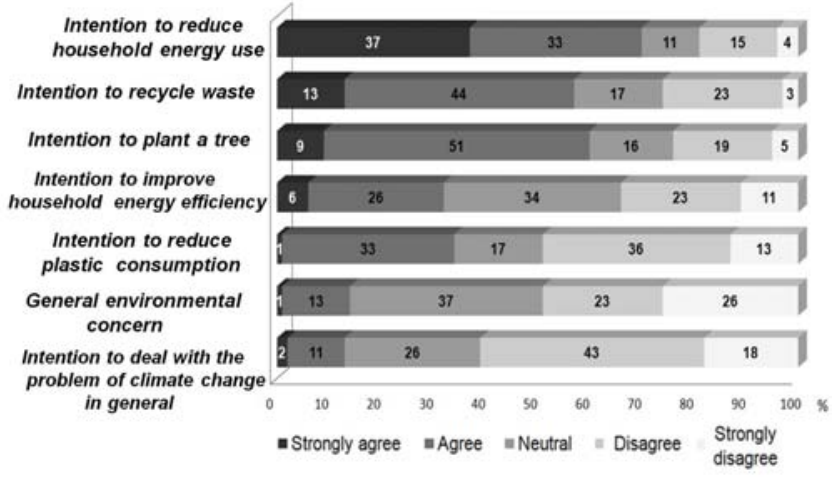

Fig. 4. Behavioral intention related to mitigation activities

\section{B. Survey and Interviews: Intentions}

As shown in Fig. 4, more than half of respondents disagreed with the statement that they have an intention to take voluntary action in dealing with climate change. Regarding their norm of attention, compared to the other problems (e.g. economic and political issues), a relatively 
small number of respondents (14\%) expressed concern for environmental problems. Moreover, interestingly, whether they know about climate change or not, the majority of respondents intended to reduce their energy consumption, separate recyclable household materials, plant trees in their community rather than reduce the use of plastic and/or installing energy efficient appliances in their home.

TABLE I: CORRELATION ANALYSIS BETWEEN CLIMATE CHANGE PERCEPTION AND THEIR BEHAVIOURS INTENTION RELATED TO MitigATION ACTIVITIES $(* P<0.05 ; * * p<0.01)$

\begin{tabular}{|c|c|c|c|c|c|c|c|c|}
\hline$\infty$ & $\begin{array}{l}\stackrel{*}{*} \\
\stackrel{*}{\rightleftharpoons} \\
i\end{array}$ & 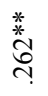 & $\overline{8}$ & $\begin{array}{l}\stackrel{*}{*} \\
\stackrel{*}{N} \\
\text { ָิ }\end{array}$ & $\frac{\infty}{\sigma}$. & $\stackrel{*}{\stackrel{*}{n}}$ & 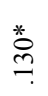 & $\underset{-}{8}$ \\
\hline$r$ & $\stackrel{\infty}{\circ}$ & $\begin{array}{l}* \\
\stackrel{*}{*} \\
\stackrel{*}{n} \\
\stackrel{?}{n}\end{array}$ & ๑ & हิ & $\bar{\sigma}_{i}$ & ğ & $\stackrel{8}{8}$ & i \\
\hline 0 & 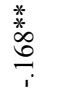 & $\underset{i}{+}$ & $\stackrel{\infty}{\infty}$ & $\begin{array}{l}* \\
\stackrel{*}{*} \\
\infty \\
\sim\end{array}$ & $\begin{array}{l}\stackrel{*}{*} \\
\stackrel{*}{+} \\
\stackrel{\infty}{+}\end{array}$ & $\underset{-}{8}$ & & I \\
\hline$n$ & $\hat{\tilde{O}}$ & $\begin{array}{l}* \\
\stackrel{*}{\circ} \\
\stackrel{\infty}{-} \\
i\end{array}$ & $\underset{i}{\stackrel{m}{S}}$ & $\begin{array}{l}\stackrel{*}{*} \\
\stackrel{*}{\circ} \\
\stackrel{n}{?}\end{array}$ & $\stackrel{8}{8}$ & $i$ & & 1 \\
\hline$\nabla$ & $\underset{i}{\stackrel{*}{g}}$ & $\stackrel{*}{\stackrel{*}{ \pm}}$ & $\stackrel{0}{0}$ & $\underset{-}{8}$ & I & i & & I \\
\hline$m$ & : & $\begin{array}{l}* \\
\stackrel{*}{*} \\
\infty \\
\infty \\
m\end{array}$ & $\stackrel{\text {. }}{\text {. }}$ & i & i & 1 & & i \\
\hline$N$ & 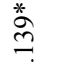 & $\underset{-}{8}$ & i & i & i & i & & I \\
\hline- & $\underset{-}{8}$ & i & i & i & i & I & & I \\
\hline 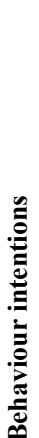 & 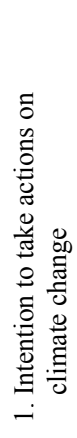 & 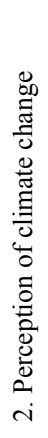 & 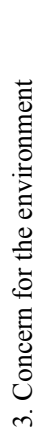 & 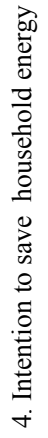 & 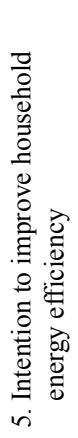 & 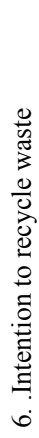 & 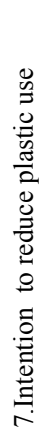 & 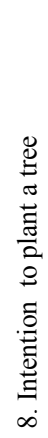 \\
\hline
\end{tabular}

To our knowledge, this is because of the general sense that it is so hard for local people to clearly differentiate between pro-environmental activities and specific actions that help to mitigate climate change. Obviously, however, almost all respondents who conserve household energy and recycle waste mostly do so for financial reasons rather than environmental preservation and climate change. The following interview statements are considered:

\section{"I have no idea how to protect our planet (e.g. environment} and climate)"

"I have a sense of helplessness sometime; I can do is very small"

"Indeed, I just would like to save more money on my electricity bill and/or make money through recycling job”

\section{Data Analysis}

Table I illustrates the relationship between the perceptions of climate change, environmental norms, and their behaviour intentions toward the specific mitigation measures. The results of correlation analysis indicate a significant positive correlation between the concern for the environment and the perception of climate change as a phenomenon $(r=.383$; $\mathrm{p}<$ $0.01)$.

Taken as a whole, the statistically significant positive correlations were found between climate change perceptions, environmental norms and behavioural intentions to take voluntary mitigation actions. In short, if the respondents have concerns about environmental issues and correctly perceived the mechanism of climate change, then they were more willing to make sacrifices to mitigate future climate change. Regarding specific mitigation measures, only the intention to plant a tree and reduce the use of plastic were found to be significantly correlated with the perceptions of climate change. Added to this, the intention to recycle household waste, implement afforestation, and reduce the usage of plastic was also positively correlated with the environmental concerns held by Thai local respondents $(\mathrm{p} \leq 0.05)$. In brief, the main purpose of each specific action is summarized in Table II.

TABLE II: Purpose of Mitigation Behaviours

\begin{tabular}{|c|c|c|c|}
\hline \multirow[b]{2}{*}{ Behaviour intentions } & \multicolumn{3}{|c|}{ Purpose of actions } \\
\hline & $\begin{array}{l}\text { Environ- } \\
\text { mental }\end{array}$ & $\begin{array}{l}\text { Climate } \\
\text { change }\end{array}$ & Economic \\
\hline $\begin{array}{l}\text { - Saving household energy } \\
\text { consumption }\end{array}$ & N/A & N/A & $\sqrt{ }$ \\
\hline $\begin{array}{l}\text { - Improving household } \\
\text { energy efficiency }\end{array}$ & N/A & N/A & N/A \\
\hline - Recycling household waste & $\sqrt{ }$ & $\mathrm{N} / \mathrm{A}$ & $\sqrt{ }$ \\
\hline $\begin{array}{l}\text { - Reducing plastic } \\
\text { consumption }\end{array}$ & $\sqrt{ }$ & $\sqrt{ }$ & $\mathrm{N} / \mathrm{A}$ \\
\hline - Increasing afforestation & $\sqrt{ }$ & $\sqrt{ }$ & $\mathrm{N} / \mathrm{A}$ \\
\hline
\end{tabular}

\section{CONCLUSIONS AND IMPLICATIONS}

Climate change has emerged as one of the biggest environmental challenges facing the world. Scientists suspect that the Earth's climate change, further accelerating global warming, is largely attributable to emission from anthropogenic activities, especially burning of fossil fuels and engaging in other form of unsustainable consumption patterns. Yet, to date, there is still an alarming gap growing between knowledge and action on climate change.

From this standpoint, this study has discovered links between climate change perceptions, environmental norms, and behavioural intentions of Thai local residents to undertake voluntary climate change mitigation actions. Our observation is that if the perception of scientific knowledge on climate change can somehow be transformed into personal concern for the environment, then perhaps people are more 
likely to change their behaviour in response to the problem accordingly. In a way, only some specific mitigation behaviours (e.g. increasing afforestation and reducing plastic consumption) were found to be significantly correlated with climate change perceptions and environmental concerns.

Throughout this study recommendations for stakeholders and possible directions for further study were raised as follows:

- Multi-stakeholders should seek out the ways to translate climate change (and/or environmental sustainability) into people's daily lives to make these issues urgent, local and personal. Complex connection between climate change and other key environmental problems should be more highlighted.

- Government should use financial incentives to increase people's environmental concerns and promote their participation in pro-environmental actions relevant to climate-change, especially the ways in which to improve their household energy efficiency.

- Different types of behavioral outcomes should focus more on a variety of socio-political and cultural preferences. Also, some core psychological components, such as self-efficacy, social competence, and sense of civic responsibility, are strongly recommended and needs further study.

\section{APPENDIX}

Appendix A: Questionnaire

\begin{tabular}{llllll}
\hline & A & B & C & D & E \\
\hline Environmental concern* & & & & & \\
$\begin{array}{l}\text { I am concerned about environmental } \\
\text { problems in my community }\end{array}$ & $\square$ & $\square$ & $\square$ & $\square$ & $\square$ \\
$\begin{array}{l}\text { Intention to tackle action on } \\
\text { climate change** }\end{array}$ & & & & & \\
$\begin{array}{l}\text { I have an intention to change my } \\
\text { behaviours to combat climate change } \\
\text { problem }\end{array}$ & $\square$ & $\square$ & $\square$ & $\square$ & $\square$ \\
Perception of climate change** & & & & & \\
\hline
\end{tabular}

I agree with the following statements

\section{Definition:}

Climate change is all change in global temperature and weather patterns over time.

\section{Its cause:}

Climate change is primary caused by fossil fuel burning (e.g. oil, coal, gas)

\begin{tabular}{|c|c|c|c|c|c|}
\hline Perception of mitigation activities** & & & & & \\
\hline $\begin{array}{l}\text { I believed that the problem of climate } \\
\text { change can be mitigated through the } \\
\text { following actions: }\end{array}$ & & & & & \\
\hline $\begin{array}{l}\text {-Saving household energy consumption } \\
\text {-Improving energy household efficiency } \\
\text {-Recycling household waste } \\
\text {-Reducing plastic consumption } \\
\text {-Increasing afforestation }\end{array}$ & $\begin{array}{l}\square \\
\square \\
\square \\
\square \\
\square\end{array}$ & $\begin{array}{l}\square \\
\square \\
\square \\
\square \\
\square\end{array}$ & $\begin{array}{l}\square \\
\square \\
\square \\
\square \\
\square\end{array}$ & $\begin{array}{l}\square \\
\square \\
\square \\
\square \\
\square\end{array}$ & $\begin{array}{l}\square \\
\square \\
\square \\
\square \\
\square\end{array}$ \\
\hline
\end{tabular}

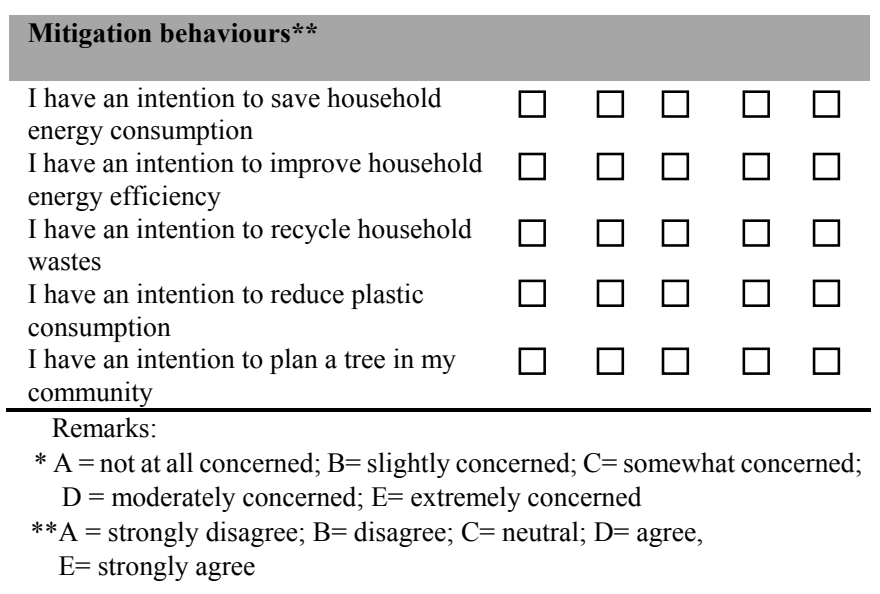

\section{ACKNOWLEDGMENT}

The author would like to express sincere appreciation to the Japanese government for providing full financial support (MEXT Scholarship) throughout this study.

\section{REFERENCES}

[1] S. R. J. Sheppard, "Landscape visualization and climate change: the potential for influencing perceptions and behavior," Environmental Science and Policy, vol. 8, pp. 637-654, 2005.

[2] A. Bostrom, M. G. Morgan, B. Fischhoff, and D. Read, "What do people know about global climate change?" Mental models. Risk Analysis, vol.14, pp. 959-970, 1994.

[3] S. L. Van der Linden, "Understanding and achieving behavioral change: Towards a New Framework for Communicating Information about Climate Change," Working paper, London, UK, 2012.

[4] S. Brechin, "Comparative public opinion and knowledge on global climate change and the Kyoto Protocol: The U.S. versus the World," Journal of Sociology, vol. 23, pp. 106-134, 2003.

[5] National Statistical Office Thailand, "National survey of Thai public opinion on the environment and climate change in 2010," Bangkok, Thailand, 2011.

[6] I. Ajzen, "The theory of planned behavior," Organizational behaviour and Human Decision Processes, vol. 50, pp. 179-211, 1991.

[7] Internatinal Energy Agency. (2001). IEA Statistics " $\mathrm{CO}_{2}$ Emissions From Fuel Combustion Highlights" [Online] Available: http:// www.iea.org/about/copyright.asp

[8] S. Kittipongvises, "Potential of clean development mechanism (CDM) activities for greenhouse gases reduction at a starch-processing factory in Thailand," Master dissertation, School of Environment, Resources and Development, Asian Institute of Technology, Thailand. 2008.

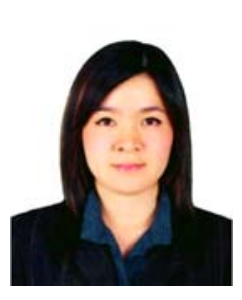

Suthirat Kittipongvises is currently a $\mathrm{PhD}$ doctoral candidate on the Graduate Program in Sustainability Science, Global Leadership Initiative (GPSS-GLI) at the University of Tokyo, Japan. She obtained a Master's degree in Environmental Engineering and Management, School of Environment, Resources and Development at the Asian Institute of Technology (AIT) in Thailand in 2008 and plans to graduate with her PhD in 2013. Her research focuses on the study of related psychological and socio-cultural factors influencing public perceptions and behavioural intentions in response to climate change. She also has presented her research at various conferences including the International Conference on Climate Change in Denmark (2009); the World Academy of Science, Engineering and Technology International Conference in Italy (2011); and the International Conference on Sustainability Science in the USA (2012). 